\title{
PT2a Stage Finding
}

National Cancer Institute

\section{Source}

National Cancer Institute. pT2a Stage Finding. NCI Thesaurus. Code C48765.

A pathologic primary tumor TNM stage finding. The definition of pT 2 a stage finding depends on the particular type of cancer that it refers to; for example, for prostate cancer, pT 2a stage finding is defined as follows: cancer limited to one-half or less of one lobe of the prostate gland; for lung cancer, pT 2a stage finding is defined as follows: cancer with a tumor size more than $3 \mathrm{~cm}$ but $5 \mathrm{~cm}$ or less in greatest dimension. (from AJCC 7th Ed.) 